\title{
Del "amigo" al "gil". Fórmulas de tratamiento y descortesía de fustigación entre jóvenes
}

\author{
From amigo to gil. Treatment formulas and \\ fustigation impoliteness among the youth
}

\author{
Gabriel Alejandro Hernández (it) \\ Universidad de Buenos Aires, Buenos Aires, Argentina \\ gabriel_alejandro_hernandez@yahoo.com.ar
}

GACCESO ABIERTO / OPEN ACCESS

Cita: Hernández, Gabriel Alejandro (2020). Del "amigo" al "gil".

Fórmulas de tratamiento y descortesía de fustigación entre jóvenes. Textos en Proceso, 6(1), pp. 82-95.

http://doi.org/10.17710/tep.2020.6.1 Shernandez

Editors: Esperanza Alcaide Lara, Universidad de Sevilla; Ana Pano Alamán, Università di Bologna

Recibido: 15/03/2020

Aceptado: 02/05/2020

Conflicto de intereses: El autor ha declarado que no posee conflicto de intereses.

Copyright: (c) Gabriel Alejandro Hernández. Esta obra está bajo licencia Creative Commons Reconocimiento 4.0.

\section{Resumen}

El objetivo del presente trabajo consiste en analizar las funciones de las fórmulas nominales de tratamiento (Rigatuso, 2011) en actos de habla descorteses de fustigación (Kaul de Marlangeon, 2005) en jóvenes de una escuela de la provincia de Buenos Aires, Argentina. La propuesta teórico-metodológica reúne desarrollos en pragmática sociocultural, metodología etnográfica y análisis de redes sociales (ARS). Como objeto de estudio, tomaré a las fórmulas nominales de tratamiento; en particular, el uso de "amigo" y "gil" en interacciones polilógicas (Hernández Flores, 2013) entre jóvenes. A partir del trabajo teórico-metodológico realizado, se espera mostrar que: 1) el uso del tratamiento "amigo", entre jóvenes que se encuentran a una distancia mínima dentro de la red de amistades, tiene por función reforzar el acto descortés de fustigación por refractariedad a los valores del grupo y 2) además de atacar la imagen del interlocutor, el uso del tratamiento referencial "gil" frente a un auditorio (Goffman, 2004) compuesto por jóvenes de la red de amigos conlleva una actividad de imagen de afiliación a los valores del grupo.

Palabras clave: imagen, descortesía de fustigación, fórmulas de tratamiento, jóvenes, interacciones polilógicas, red social.

\footnotetext{
Abstract

The objective of this work is to analyze the functions of nominal treatment formulas (Rigatuso, 2011) in impolite speech act of whipping (Kaul de Marlangeon, 2005) in young people from a school in the province of Buenos Aires, Argentina. The theoretical-methodological proposal includes developments in sociocultural pragmatics, ethnographic methodology and analysis of social networks (ARS). As an object of study, I will take the nominal treatment formulas; in particular, the use of "amigo" and "gil" in polylogical interactions (Hernández Flores, 2013) among young people. Based on the theoretical-methodological work carried out, it is
} 
expected to show that: 1) the use of the "friend" treatment, among young people who are at a minimum distance within the network of friends, has the function of reinforcing the impolite speech act of whipping by refracting the values of the group and 2) in addition to attacking the image of the interlocutor, the use of the referential treatment "gil" in front of an audience (Goffman, 2004) made up of young people from the network of friends involves an image activity of affiliation with the values of the group.

Keywords: image, impoliteness of fustigation, treatment formulas, young boys, polylogical interactions, social network.

\section{Introducción}

El presente trabajo forma parte de una investigación a largo plazo ${ }^{1}$ cuyo objetivo radica en analizar las funciones de las fórmulas de tratamiento en actos de habla descorteses y anticorteses (Zimmerman, 2005) utilizadas por grupos de jóvenes de dos escuelas de la provincia de Buenos Aires, Argentina. Para ello, utilizo un marco teórico-metodológico que integra aportes de la pragmática sociocultural, la etnografía de la comunicación y la metodología del análisis de redes sociales.

Dentro de este panorama general, el objetivo de esta presentación consiste en analizar funciones de fórmulas de tratamiento (Rigatuso, 2011) en actos de habla descorteses de fustigación (Kaul de Marlangeon, 2005) entre los integrantes de un grupo de jóvenes. En particular, propongo enfocarme en el uso de "amigo" y "gil".

El corpus general de esta investigación se construyó a partir del trabajo de campo realizado en la escuela de educación secundaria ${ }^{2} \mathrm{~N}^{0} 12$ del partido de San Fernando, provincia de Buenos Aires, durante los meses de agosto a diciembre de 2019. Puntualmente, en este artículo se analizará una interacción polilógica (Hernández Flores, 2013) ocurrida en una clase de Matemáticas, entre jóvenes con edades comprendidas entre 17 y 18 años. Se llevó a cabo una triangulación metodológica que implicó un abordaje etnográfico, entrevistas a los jóvenes y distribución de cuestionarios impresos con preguntas sobre las características de sus relaciones entre pares y amigos. A partir de los datos obtenidos de esta triangulación se generó una red con el software NodeXL, donde los jóvenes constituyeron los nodos, mientras que los vínculos de amistad configuraron los lazos.

La variación del tipo de efecto puede estar relacionado con la distancia interpersonal y la afiliación a un determinado grupo. En este sentido, para indagar las relaciones entre el uso de tratamientos en actos descorteses y la distancia interpersonal entre los jóvenes se utilizó la distancia geodésica, definida como el número de relaciones en el camino más corto posible de un participante a otro dentro de la red (Hannemann, 2000). Asimismo, la centralidad por grados de salida, entendida como la cantidad de lazos de amistad de cada joven dentro de la red, nos

\footnotetext{
${ }^{1}$ La presente investigación se enmarca en una beca de posgrado otorgada por la Universidad de Buenos Aires, para desarrollar la tesis "Un abordaje interdisciplinario sobre el uso de insultos en jóvenes de una escuela de provincia de Buenos Aires" en el doctorado en Lingüística (UBA) y forma parte del Proyecto de Grupo de Investigación UBACyT "La imagen de la política y la política de la imagen: análisis de las transformaciones en los sistemas semióticos de las prácticas políticas en la Argentina post 2001", dirigido por la Dra. Julia Zullo

${ }^{2}$ Para el proyecto de tesis, se realizó trabajo de campo en dos establecimientos educativos de la zona norte del conurbano bonaerense durante el año 2019: una escuela privada en la zona de San Isidro de nivel socioeconómico alto y una escuela pública de San Fernando.
} 
resultará útil para entender las actividades de imagen y los efectos de descortesía en interacciones polilógicas.

A partir de este abordaje teórico metodológico se espera mostrar que entre jóvenes que se encuentran a una distancia geodésica de 1 dentro de la red de amistades, el uso de la fórmula de tratamiento "amigo" refuerza el acto descortés de fustigación por refractariedad al grupo. A su vez, el uso del tratamiento referencial "gil" frente a un auditorio (Goffman, 2004) compuesto por jóvenes de la red de amigos conlleva una actividad de imagen de afiliación a los valores del grupo.

\section{Marco teórico}

Dentro de la pragmática sociocultural, Bravo (1999) propone que la imagen social presenta ciertos contenidos de imagen, surgidos de la formulación de un valor cultural, una creencia, el reflejo de un comportamiento habitual en una determinada situación, etcétera. Estos contenidos de imagen social son la afiliación, que refiere al individuo auto percibido y percibido por otros como parte de un grupo, y la autonomía, que refiere al individuo que se percibe a sí mismo y es percibido a su vez con un contorno definido dentro del propio grupo (Bravo, 1999).

Por su parte, las actividades de imagen son aquellas que tienen una influencia sobre la imagen de los interlocutores: se trata de cómo ego se ve a sí mismo, como ve a los otros y como cree que los demás lo ven en un contexto determinado (Bravo 2002). Esta categoría analítica de imagen está asociada a la actividad comunicativa de la cortesía, entendida como "una actividad comunicativa cuya finalidad propia es quedar bien con el otro y que responde a normas y a códigos sociales que se suponen en conocimiento de los hablantes" (Bravo, 2005, pp. 33-34).

También dentro de esta corriente, Bernal entiende que la descortesía "consiste en una actividad comunicativa cuya finalidad es dañar la imagen del otro y que responde a códigos sociales supuestamente compartidos por los hablantes. En todos los contextos considera el perjuicio del interlocutor" (Bernal, 2008, p. 777). En este sentido, los actos de habla descorteses son actos que atacan la imagen del interlocutor pues pretenden hostigarla o denigrarla de manera intencional (Bernal, 2007).

En consonancia con los planteos pioneros de Lavandera (1988) sobre la fuerza de cortesía-descortesía, Kaul de Marlangeon (2005) concibe al sector de la descortesía como un continuo de amenazas a la imagen del destinatario. Así, la autora elabora una tipología de actos descorteses. Dentro de ésta, nos centraremos en la descortesía de fustigación, constituida por "comportamientos volitivos, conscientes y estratégicos, destinados a herir la imagen del interlocutor, para responder a una situación de enfrentamiento o desafío, o con el propósito de entablarla" (Kaul de Marlangeon, 2005, p. 302).

El trabajo teórico de Kaul de Marlangeon retoma la perspectiva sociocultural de Bravo (1999, 2002 y 2003) y sus categorías de afiliación y de autonomía para comprender los contenidos de imagen social. De esta manera, Kaul de Marlangeon establece una distinción dentro de la descortesía de fustigación. En primer lugar, por afiliación exacerbada, entendida como verse y ser visto como adepto al grupo. El hablante "agrede al oyente porque percibe en éste una gran autonomía respecto del grupo u oposición al grupo y que, cuando el hablante se encuentra en autonomía exacerbada respecto del grupo u oposición a éste, agrede al oyente porque percibe 
en éste su afiliación a los valores del grupo" (Kaul de Marlangeon, 2005, p. 303). En segundo lugar, la descortesía por fustigación también puede ser por refractariedad, entendida como la autonomía exacerbada de verse y ser visto como opositor al grupo, donde el hablante "quiere expresar que está en una actitud refractaria respecto de aquello que suscita su oposición" (Kaul de Marlangeon, 2005, p. 303).

Dentro de los actos descorteses de fustigación, tomaré como objeto de estudio a las fórmulas de tratamiento, entendidas como "el conjunto de formas que poseen los hablantes para dirigirse al destinatario y hacer referencia a una tercera persona y a sí mismos en el mensaje" (Rigatuso, 2010, p. 377). La presencia de las fórmulas de tratamiento nos indica relaciones interpersonales de los hablantes y pueden constituirse como marcadores de identidad individual o grupal. Tal como enuncia Rigatuso:

Por su índole social, interaccional e identitaria las fórmulas de tratamiento y los fenómenos de (des)cortesía constituyen potentes generadores de reflexiones metalingüísticas por parte de los hablantes, que revelan sus percepciones y evaluaciones sobre determinados fenómenos y comportamientos sociales (p. 383).

Para el presente estudio, me centraré en las fórmulas nominales de tratamiento "amigo" y "gil" en actos descorteses de fustigación dentro de un tipo particular de interacciones, las interacciones polilógicas (Hernández Flores, 2013). Éstas integran a diferentes participantes que, aunque no tomen turnos de habla, se encuentran presentes en la escena y conforman parte del auditorio (Goffman, 2004). Esto es importante ya que, aunque la actividad comunicativa se dirige hacia una persona, las imágenes de los demás también se ven afectadas en virtud de su coparticipación en la interacción: el efecto de descortesía es multidireccional porque existen múltiples efectos sobre la imagen de un mismo hablante. Por su parte, el concepto de efecto social remite a las consecuencias que puede tener una actividad comunicativa sobre el clima socioemocional de la interacción (Bravo, 2002). En el caso de la descortesía, el efecto es negativo para la imagen del interlocutor.

\section{Metodología}

\subsection{Trabajo de campo}

Como se enunció anteriormente, la etnografía de la comunicación y el análisis de redes sociales forman parte de la triangulación metodológica. El corpus se construyó a partir de una etnografía realizada en la escuela de educación secundaria $\mathrm{N}^{0} 12$ del partido de San Fernando, provincia de Buenos Aires, durante los meses de agosto a diciembre de 2019. Como parte del componente etnográfico, en esta institución se realizó observación participante, que abarca un espectro amplio de actividades, "desde un simple estar allí como un testigo mudo de los hechos hasta el hecho de realizar una o varias actividades de distinta envergadura y con distintos grados de involucramiento personal, político y social" (Guber, 1991, p.119).

Para el presente trabajo, se observó una interacción (Tusón, 1997) ocurrida en una clase de Matemáticas entre cuatro alumnos de 6to año: Fabricio, Milton, Mateo y Damián. La interacción es polilógica y el efecto de descortesía es multidireccional: no se restringe solo a Fabricio, Milton, Mateo y Damián, sino también al resto de los presentes en el espacio áulico.

El registro se formó a partir de la grabación sonora y la posterior toma de notas de campo. También se realizaron entrevistas no directivas (Guber, 1991) a los 
jóvenes para acceder al contexto del usuario (Bravo, 1999). Los nombres de todos los jóvenes fueron cambiados para garantizar el anonimato.

\subsection{Análisis de redes}

Junto al enfoque etnográfico se utilizó el análisis de redes sociales (ARS), entendiendo por red social a "un conjunto finito de actores o grupos de actores y las relaciones definidas entre ellos" (Requena Santos y Ávila Muñoz, 1998, p. 653). El ARS permite comprender de qué manera las relaciones entre los participantes se estructuran para otorgar al grupo una topología determinada.

Existen diversos enfoques dentro del análisis de redes sociales: redes semánticas, que indagan en la representación del conocimiento de un individuo o grupo (Verd Pericás, 2005; Lonkila y Harmo, 1999), análisis de redes de palabras, cuyo objetivo radica en conocer cuáles son los conceptos comunes dentro de un conjunto dado de actores (Verd Pericás, 2005, p. 133) y análisis de redes textuales, donde el sentido del texto no viene dado por las palabras en sí mismas, sino por su organización en red. En particular, utilizaré el enfoque de redes semánticas (Verd Pericás, 2005), para indagar las representaciones sobre los lazos de amistades y mapear los efectos sociales de los actos descorteses de fustigación en esta interacción polilógica.

A partir de los datos que los informantes volcaron en los cuestionarios sobre quiénes consideraban que eran sus amigos se construyó una red percibida de amistades entre los jóvenes, sustentada "en lo que uno o más participantes pueden decir de sus contactos en un grupo social, y reconoce como ámbito de validación la opinión de los propios integrantes" (Miceli, 2008, p. 9). Esto configura una red de segundo orden, ya que involucra una representación de las representaciones de los lazos efectuadas por los jóvenes (Miceli, 2008).

Uno de los intereses más comunes del análisis de redes radica en las subestructuras o subgrupos que pueden estar presentes en una red, tales como las díadas, tríadas y círculos ego-centrados. Desde este enfoque, nos basamos en las redes de amistades de cuatro jóvenes: Fabricio, Milton, Mateo y Damián. Con los datos del cuestionario se generó un grafo de red de amistades autopercibidas en el software NodeXL, a partir de la utilización del método de muestreo de redes egocéntricas con conexiones a otros (Hannemann, 2000). Así, partimos de un conjunto de cinco nodos focales (los participantes de la interacción) e identificamos los nodos con los que ellos están conectados:

Ilustración 1. Grafo de red de amistades autopercibidas. En rojo, los nodos focales. 


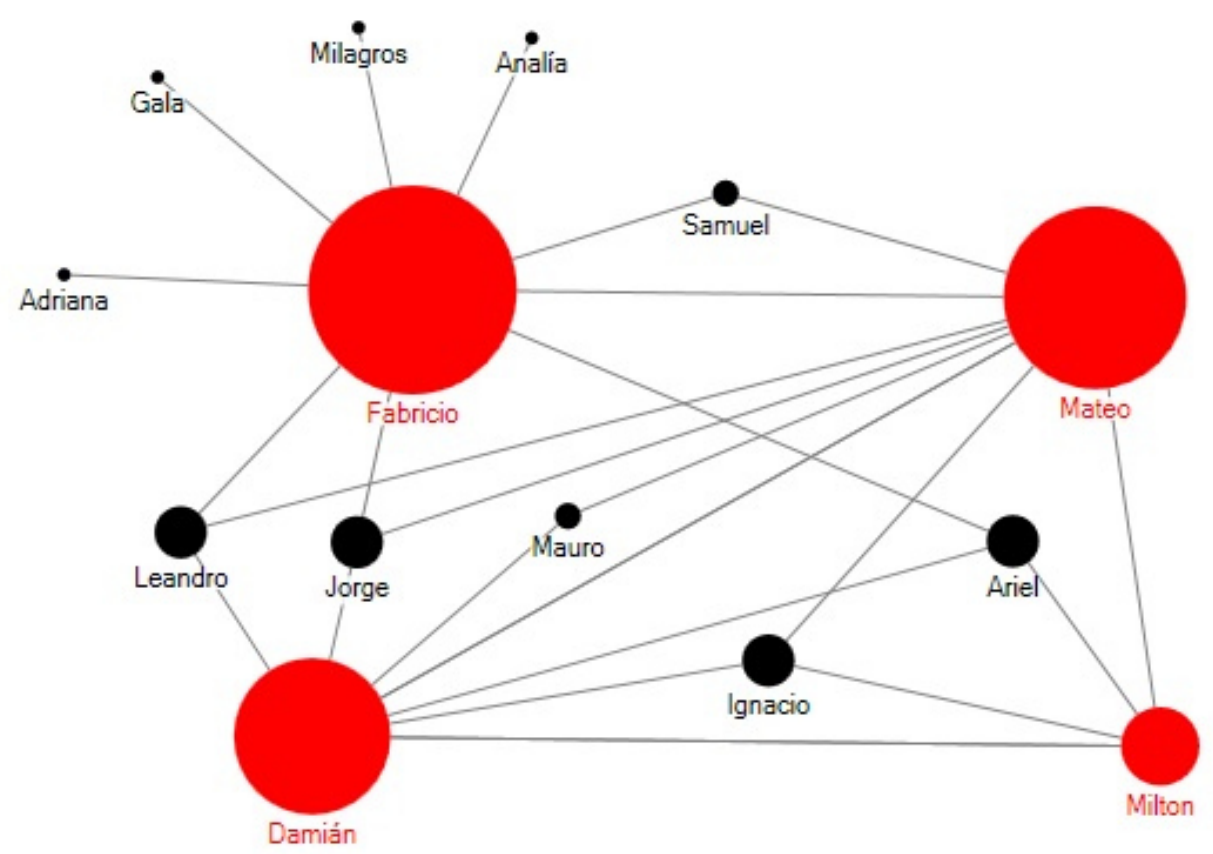

La red de la Ilustración 1 cuenta con 14 nodos y un total de 24 lazos. Esta red de amistades presenta una densidad de 0,27 ; es decir, que solo está presente el $27 \%$ de todas las relaciones posibles entre los jóvenes.

Al utilizar el análisis de redes se debe detectar qué algoritmo es más acorde a determinada topología de la información que se analiza (Miceli, 2008). Para indagar las relaciones entre el uso de tratamientos en actos descorteses y la distancia interpersonal entre los jóvenes se utilizó la distancia geodésica, entendida como el número de relaciones en el camino más corto posible de un participante a otro dentro de la red (Hannemann, 2000). Asimismo, esta medida reticular nos resultará importante para entender las actividades de imagen en interacciones polilógicas. Como sostiene Hernández Flores (2013), consideramos, que la variación del tipo de efecto puede estar relacionado con la afiliación de los jóvenes a un determinado grupo (para nuestro caso, la red de amistades) y la distancia interpersonal (la distancia geodésica).

Por su parte, el tamaño de los nodos indica la medida de la centralidad de grados de salida. Tal como postula Hannemann (2000), la medida de grado nos puede dar una idea de jerarquías al interior de los grupos, ya que "los actores que inusualmente tienen un alto grado de salida son actores que son capaces "de intercambiar con muchos otros, o hacer a muchos otros conscientes de sus puntos de vista" (Hannemann, 2000, p. 47). En este caso, los mayores nodos los constituyen Fabricio, Milton, Mateo y Damián.

\section{Análisis}

\subsection{La interacción}

La situación registrada fue una discusión entre alumnos. La interacción (Tusón, 1997) fue tomada como la unidad dialogal más abarcadora; contiene una secuencia, que comienza con la entrada de un participante y finaliza con la salida de éste. Esta secuencia consta de un total de ocho turnos de habla. Luego, en el siguiente apartado, se va a llevar a cabo el análisis. 
La interacción ocurrió el 6 de septiembre de 2019 en la escuela de educación secundaria $\mathrm{N}^{0} 12$. En el recreo de la mañana, Milton, de 6to año, tuvo lugar una pelea verbal y física con un alumno de 5to en el baño de la escuela, que resultó herido en una oreja. Como Milton es mayor de edad, el director se vio en la obligación legal de llamar a la Policía y el alumno fue retenido en Dirección. Luego, en la hora de Matemáticas, Milton entró al aula para buscar su mochila y su campera, que estaban en el banco que compartía con Damián. Milton le dijo a Damián que se tenía que ir con la Policía y se registró la interacción. Para que el lector comprenda los coloquialismos expresivos verbales, se explicarán los mismos como nota al pie de página.

1) Damián: Cinco veces te dije que $=$ salgas de $(())=$

Milton: $=$ ¿Y por qué no $=$ lo agarraste $\gtreqless$ ¿Por qué no $=$ lo agarraste? ¿Pero si el chabón ${ }^{3}$ me agarraba del brazo a mí como no le vas a pegar? ¿Eh?

Preceptora: $=$ Milto::n $/$

Milton: $[$ mira a Diego $]=\succsim$ Vos te $=$ pensás que yo me voy a dejar pegar? $\mid$ Sos re $\mathrm{r}^{4}$ trolo ${ }^{5}$ amigo

Matías: Tomatela [mira a Milton y levanta la mano derecha]

Milton: [mira a Damián mientras se pone la campera] sos re trolo $\|$ sos re puto

Damián: Vos sos re puto

[Milton chasquea la lengua, levanta la mano derecha y agarra su mochila. Antes de cruzar la puerta del curso, le pega en la visera a Fabricio que estaba sobre el banco y ésta cae al piso]

Fabricio: [Mientras Milton cierra la puerta con un portazo fuerte, mira a Damián] Está re zarpado ${ }^{6}$ el gil $^{7}$ | lo voy cagar a piñas ${ }^{8}$ [Los alumnos comienzan a gritar y hablar sobre lo sucedido. La preceptora pide calma].

\section{2 "Sos re trolo, amigo". Distancia interpersonal y función del tratamiento nominal en un acto descortés de fustigación}

En el turno 1, Damián lleva a cabo un acto de habla expresivo descortés, una recriminación. Conlleva un ataque a la imagen de Milton, como un joven que no puede controlar sus impulsos. En 2, las preguntas “¿Por qué no = lo agarraste?” y “¿Pero si el chabón me agarraba del brazo a mí como no le vas a pegar?” pueden ser englobados dentro de la definición de un acto de habla indirecto que se produce cuando "un acto ilocucionario se realiza indirectamente al realizar otro" (Searle, 1977, p. 24). En este caso se trata de una pregunta que funciona como una recriminación. Milton esperaba otro tipo de comportamiento por parte de Damián, en virtud de la relación de amistad que los une.

En 3 la preceptora tiene una breve participación; utiliza una forma nominal para mitigar y frenar la creciente escalada del conflicto. Por su parte, el turno de habla 4 se compone de dos actos de habla. Primero aparece un acto indirecto descortés, una pregunta retórica donde el hablante despliega una actividad de autoimagen positiva, donde Milton pone en valor su comportamiento defensivo ante un ataque físico. Segundo, un acto descortés de fustigación donde aparece la fórmula nominal de tratamiento "amigo" pospuesta al acto fustigador "Sos re trolo".

\footnotetext{
${ }^{3}$ Vocativo utilizado para referirse a una persona a la que no se conoce o de la que se desconoce su nombre.

${ }^{4}$ Intensificador.

${ }^{5}$ Adjetivo coloquial y despectivo. Homosexual.

${ }^{6}$ Que se comporta inadecuadamente o dice cosas que resultan groseras, indiscretas o inoportunas.

${ }^{7}$ Persona de escasas facultades mentales.

${ }^{8}$ Expresión utilizada como amenaza de agresión física.
} 
Según Rigatuso (1994), en el español rioplatense actual existen formas nominales que se organizan en dos subcategorías claramente definibles: nombre personal y términos de tratamiento. Dentro de estos últimos, existen los términos de parentesco, formas de trato social de índole general (señor, doña), ocupacionales o de amistad, cordialidad y afecto, tales como "amigo". Para comprender el uso y función de este tratamiento dentro de un acto descortés recurrimos a entrevistas no directivas (Guber, 1991) para acceder al contexto del usuario (Bravo 1999):

2) Samuel: Igual el que tiene también muchos sentidos ahora es "amigo". "Amigo" te lo puede decir un amigo verdadero

Milton: "Eh amigo", “perro", “qué onda gato", “qué onda compa”, “qué onda ñeri” una banda de cosas

Samuel: O también para llamarte, o sea si vos por ahí a la calle te preguntan “¿amigo me decís la hora?”.

El fenómeno de los usos positivos y negativos de tratamientos nominales se ha estudiado tanto para el uso del "boludo" en Argentina (Ramírez Gelbes y Estrada, 2010), el "huevón" en Chile (Helinkcs, 2015) o "mate" (Rendle-Short, 2010) en Australia. Particularmente, el uso de "amigo" presenta algunas similitudes con el uso de "mate" (compañero o compañera) que analiza Rendle-Short (2010) en interacciones cotidianas entre australianos. Esta fórmula de tratamiento puede utilizarse entre amigos, pero también entre conocidos casuales y puede interpretarse de forma positiva como un término amistoso, y otras veces puede interpretarse de forma negativa y hasta incluso como hostil.

En términos de redes, encontramos dos usos de "amigo": por un lado, en actos de habla indirectos, más específicamente, en preguntas que funcionan como pedidos a personas que no están dentro de su red de amistades; por otro lado, para ser utilizado con jóvenes que se encuentran a una distancia geodésica mínima dentro de la red de amistades autopercibidas. En este sentido, si relacionamos el tratamiento "amigo" en el acto descortés con la posición de los nodos en la red, encontramos que la actividad comunicativa en el turno de habla 4 se dio entre participantes que encuentran a una distancia geodésica de 1 dentro de la red.

Ilustración 2. Actividades comunicativas en la red de amistades autopercibidas. La flecha indica la dirección de la actividad comunicativa en el turno de habla 4. 


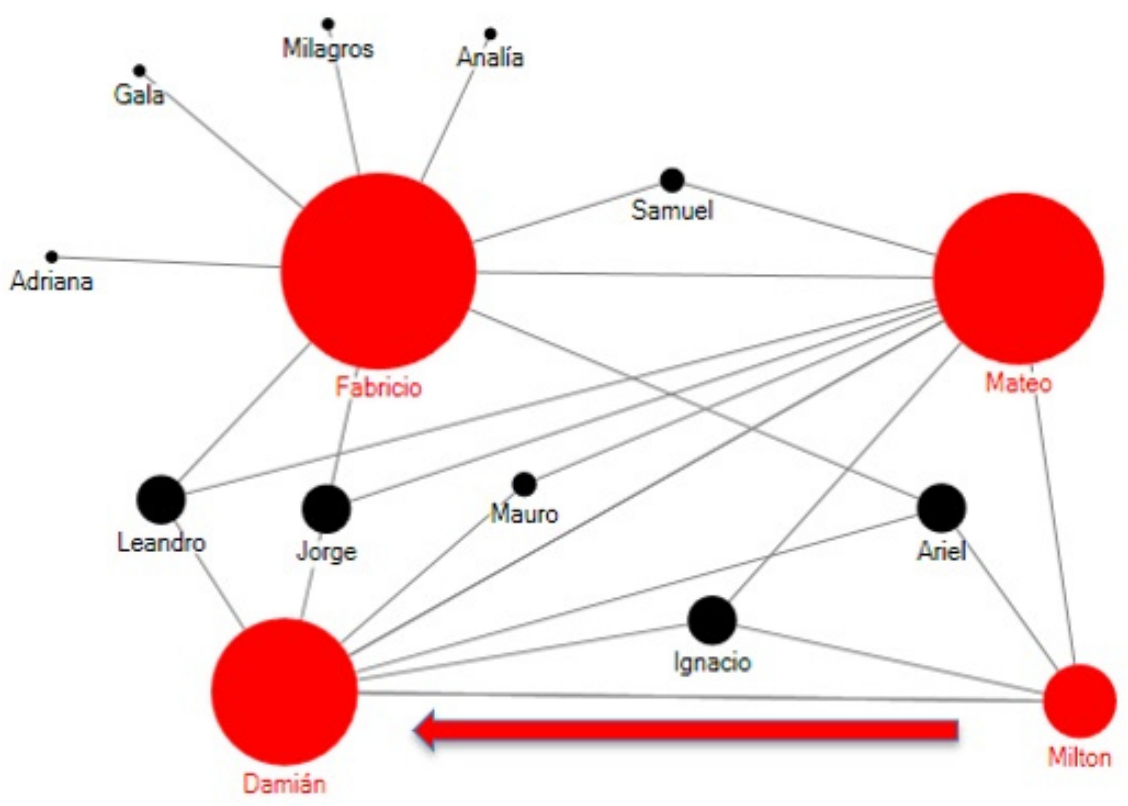

Esta distancia mínima dentro de la red fue importante a la hora de indagar los diferentes usos de "amigo" en las entrevistas no directivas:

3) Investigador: En ese caso, si ustedes quieren rebajar a alguien, ¿cómo lo harían? Samuel: Con "amigo" nunca lo podés rebajar, a un amigo no lo rebejaría nunca. Mateo: Ponele para que se rescate sí, ponele

Samuel: Bueno ahí sí pero eso no es rebajar tampoco, ahí lo ponés en su lugar.

La categoría nativa de "rescate" se utiliza para señalar que alguien debe necesariamente volver a los límites aceptados, de lo contrario la situación puede derivar en la agresión física (Hernandez, 2014). Esta categoría nativa, en este caso asociado a la fórmula de tratamiento "amigo", alude al respeto de las normas sociales que rigen una interacción, y puede aparecer como una conducta preventiva frente a la transgresión o bajo la forma de un verbo imperativo ("rescatate") dirigido hacia una persona que incurre en una transgresión (Hernandez, 2014).

En suma, el acto de habla "Sos re trolo, amigo" es un acto descortés de fustigación por refractariedad. Milton arremete y expresa una actitud refractaria respecto de aquello que suscita su oposición. Al utilizar la fórmula nominal de tratamiento "amigo" en un acto descortés, Milton ataca la imagen de Damián: en virtud de la relación interpersonal que los une, queda amenazada su imagen como amigo, ya que de él se espera que utilice la fuerza física para defender a otro en un conflicto. En categorías nativas, esto se conoce como "rescate". Por lo tanto, "amigo" tiene la función de reforzar el acto descortés.

\section{3 "Está re zarpado el gil". Efectos de la fustigación en interacciones polilógicas}

Como vimos, en el turno 4 hay un acto descortés de fustigación. Luego, en el turno de habla 5, Mateo interviene con un acto directivo, una orden, para evitar que el conflicto escale. Luego, Milton utiliza un acto descortés de fustigación en 6 hacia Damián; éste devuelve la ofensa que le inflige Milton con un contraataque y repite el mismo acto descortés recibido ("Vos sos re puto"). Podemos decir, entonces, que en los turnos de habla 4, 5, 6 y 7 tenemos los pares básicos de la interacción 
descortés (Harris, Gergen y Lannaman, 1986): hablante ofensivo - oyente defensivo y hablante ofensivo - oyente ofensivo. Luego, Milton se retira de la interacción y en el turno de habla 8, Fabricio utiliza un acto descortés ("Está re zarpado el gil") con presencia de la fórmula de tratamiento referencial "gil" (a una tercera persona) y una expresión de deseo ("lo voy a cagar a piñas").

Como afirma Hernández Flores (2013), aunque la actividad comunicativa se dirija a una sola persona, las imágenes de los demás presentes también se ven afectadas debido a su coparticipación en la interacción. El efecto de descortesía no se restringe solo a Milton, Fabricio, Damián y Mateo, sino también al resto de los alumnos del curso, la profesora de Matemáticas y a la preceptora, presentes en ese momento en el aula.

La fórmula de tratamiento "gil" es similar a "tonto" y destaca la falta de inteligencia. Fabricio dirige este acto a Damián frente a un auditorio de amigos constituido por una red de amistades presentes en la interacción. Es de destacar que en la interacción no se encontraban presentes Ignacio y Ariel, dos jóvenes que se encuentran a una distancia geodésica de 1 de Milton y que potencialmente podrían defenderlo del ataque.

La estrategia de Milton de atacar a Damián frente a los amigos de éste no logró destruir su imagen; por el contrario, suscitó una actividad de imagen de afiliación al grupo por parte de Fabricio. Si pensamos en términos de redes, el mayor tamaño de los nodos "Fabricio" y "Damián" se debe a la cantidad de lazos de amistades que poseen, y eso configura también un tipo especial de prestigio dentro de la red de amistades. Al tratar a Milton como "gil" dentro de un acto descortés, Fabricio ataca a la imagen de éste al ligarla al descontrol:

4) Investigador: Yo me acuerdo de que hace dos semanas hubo acá un quilombo ${ }^{9}$, una pelea en el baño. ¿Recuerdan si hubo algún tipo de insulto?

Adriana: Sí, un compañero le dijo al otro que por qué no se metió y le dijo que era puto y demás porque no se había metido en la pelea. Entonces bardeó zarpdo y entonces el otro saltó.

La categoría nativa de "bardo" se relaciona con la transgresión, con el traspaso de límites sociales: "Bardear, bardero, descontrolar, descontrolado. Tiene en realidad múltiples significados o, mejor dicho, múltiples aplicaciones de signo positivo y negativo. Pero el hecho de que se use el mismo vocablo está indicando algo común en los distintos sentidos: traspasar cierto límite o cierta regla" (Bustos Castro 2005, en Margulis, 2005, p. 71). Estas aplicaciones de las categorías nativas se vislumbran en las entrevistas:

5) Ignacio: Bardear es putear

Mateo: También puede ser bardear, hacer una cagada

Milton: O si rompés algo, "Uh la re bardiaste amigo".

Tal como enuncia Hernández Flores (2005), la imagen del hablante descortés es afectada por su propio comportamiento, pues normalmente quedará en una situación negativa por el rechazo y desprecio que puede producir en sus interlocutores. En esta interacción, el efecto social que logra Milton al utilizar un acto descortés por fustigación a un amigo fue el de unir al grupo para sancionar su comportamiento. Si bien los jóvenes se quejaron de las provocaciones de los jóvenes

${ }^{9}$ Lío, barullo, gresca, desorden. 
de quinto año, Milton traspasó un límite ya que aquél que "bardea" rompe con las convenciones lingüísticas y sociales de la interacción, generando roces y conflictos (Hernandez, 2014).

Fabricio, entonces, utilizó un acto descortés de fustigación por afiliación exacerbada a los valores del grupo (Kaul de Marlangeon, 2005): agrede a Milton porque percibe en éste una gran autonomía respecto del grupo. La agresión proviene de su convicción de tener de su parte al grupo, lo cual lo distancia de este joven y le asegura el efecto de descortesía.

\section{Conclusiones}

Tal como enuncia Rigatuso (2000), las fórmulas de tratamiento se revelan como importantes marcadores de las relaciones interpersonales de los hablantes. Una cuestión pragmática para relevar se vincula con los usos de los tratamientos en términos de las variables de solidaridad y el poder en las relaciones (Brown y Gilman, 1960). Para el presente estudio, exploramos dichas variables con dos medidas reticulares: distancia geodésica para mapear la solidaridad en los vínculos y centralidad por grado de cercanía para explorar la variable del poder en interacciones polilógicas.

En primer lugar, destacamos que la fórmula nominal de tratamiento "amigo" no se puede encasillar a priori en una estrategia particular de cortesía. En el caso analizado, la función de este tratamiento es reforzar el acto descortés de fustigación por refractariedad: refuerza el ataque a la imagen social, en virtud de la relación interpersonal que une a Damián y a Milton. Ambos jóvenes se encuentran a una distancia geodésica de 1 dentro del grafo de redes de amistades autopercibidas.

Al tratarse de una interacción polilógica, pusimos en consideración el efecto del acto descortés sobre el auditorio presente. El acto descortés de fustigar a Damián no ocasionó un daño efectivo a la imagen de éste como amigo, más bien dañó la imagen de Milton ante la red de jóvenes, al mostrarse como una persona descontrolada y ligada a la categoría nativa de "bardo".

En segundo lugar, el tratamiento referencial "gil" utilizado por Fabricio refuerza el contenido sociocultural de mostrarse como parte integrante del grupo que en ese contexto se trata de los jóvenes presentes en la interacción polilógica. La agresión que Fabricio le inflige a Milton proviene de su convicción de tener de su parte al grupo. En términos de redes, esto condice con el tamaño del nodo Fabricio: como tiene la mayor de cantidad de vínculos en la red, posee el mayor grado de centralidad, seguido por Mateo y Damián.

A partir de este diálogo interdisciplinar, queda por delante profundizar críticamente los alcances, límites y potencialidades del ARS dentro del campo del estudio de las fórmulas de tratamiento entre jóvenes y explorar si estos usos son extensivos hacia otros subgrupos de amigos de otras instituciones educativas. En particular, la relación teórica y metodológica entre los estudios sobre fórmulas de tratamiento, descortesía de fustigación, actividad de imagen y las medidas reticulares mencionadas se reveló como un camino fértil para comprender las estrategias de descortesía que utilizan y los efectos que producen. Para ulteriores desarrollos, se espera listar los lazos dentro de una red de amistades y la presencia de los tratamientos "amigo" y "gil" en actos descorteses de fustigación entre diversos nodos de la red de amigos. De esta manera, se podría corroborar una correspondencia más estricta entre este continuum de intensidad entre la cortesía y la descortesía y las distancias de red. 


\section{Referencias}

1. Bernal, M. (2007). Categorización sociopragmática de la cortesía y de la descortesía. Un estudio de la conversación coloquial española. Estocolmo: Universidad de Estocolmo.

2. Bernal, M. (2008). ¿Insultan los insultos? Descortesía auténtica vs. Descortesía no auténtica en español coloquial. Pragmatics, 18(4), pp. 775-802.

3. Bravo, D. (1999). ¿Imagen positiva vs. Imagen negativa? Pragmática sociocultural y componentes de face. Oralia. Análisis del discurso oral, 2, pp. 155-184.

4. Bravo, D. (2002). Actos asertivos y cortesía: Imagen del rol en el discurso de los académicos argentinos. En Placencia, M. E. y Bravo, D. (Eds.), Actos de habla y cortesía en español (Vol. 5, pp. 141-172). Múnich: Lincom Studies in Pragmatics.

5. Bravo, D. (2003). Actividades de cortesía, imagen social y contextos socioculturales: Una introducción. En Actas del Primer Coloquio del programa EDICE. La perspectiva no etnocentrista de la cortesía: identidad sociocultural de las comunidades hispanohablantes (pp. 98-108) Estocolmo: Universidad de Estocolmo. Recuperado de: www.edice.org.

6. Brown, R., y Gilman, A. (1960). The pronouns of power and solidarity. En Sebeok, T. A. (Ed.), Style in Language (pp. 253-276). Cambridge: MIT Press.

7. Bustos Castro, P. (2005). El recital: Los militantes del bardo. En Margulis, M. (Ed.). La cultura de la noche: La vida nocturna de los jóvenes en Buenos Aires (pp. 51-76). Buenos Aires: Biblos.

8. Goffman, E. (2004). La presentación de la persona en la vida cotidiana. Buenos Aires: Amorrortu.

9. Guber, R. (1991). El salvaje metropolitano. A la vuelta de la Antropología Posmoderna. Madrid: Legasa.

10. Hannemman, R. (2005). Introducción a los métodos del análisis de redes sociales. Departamento de Sociología de la Universidad de California Reverside. Recuperado de: http://revistaredes.rediris.es/webredes/textos/cap8.pdf.

11. Harris, L., Gergen, K., \& Lannaman, J. (1986). Aggression rituals. Communication Monographs, 53, pp. 252-265. DOI : https://doi.org/10.1080/03637758609376140

12. Helincks, K. (2015). La forma de tratamiento nominal huevón en Iquique (Chile): Análisis empírico de conversaciones cotidianas informales. Onomázein, 32, pp. 132-151. DOI:

https://doi.org/10.7764/onomazein.32.7

13. Hernandez, G. (2015). Manifestación de la descortesía y anticortesía en jóvenes de la Provincia de Buenos Aires, Argentina. Usos y representaciones de malas palabras e insultos. Revista Signo y Seña, 26, pp. 23-47. DOI: https://doi.org/10.15174/au.2013.492

14. Hernández Flores, N. (2013). Actividad de imagen: Caracterización y tipología en la interacción comunicativa. Pragmática Sociocultural, 1(2), pp. 175-198. DOI: https://doi.org/10.1515/soprag-2012-0012

15. Kaul de Marlangeon, S. (2005). Descortesía de fustigación por afiliación exacerbada o refractariedad. El discurso tanguero de la 
década del '20. En Bravo, D. (Ed.), Estudios de la (des)cortesía en español: categorías conceptuales y aplicaciones a corpora orales y escritos (Vol. 1, pp. 299-318). Buenos Aires: Programa EDICE/DUNKEN.

16. Kaul de Marlangeon, S. (2012). Encuadre de aspectos teóricometodológicos de la descortesía verbal en español. En Morales, J. E. y Vega, G. H. (Eds.), Miradas multidisciplinares a los fenómenos de cortesía y descortesía en el mundo hispánico (pp. 76-106). Barranquilla: Universidad del Atlántico/Programa EDICE.

17. Kaul de Marlangeon, S. (2014). Delimitación de unidades extralingüísticas de análisis del discurso de (des)cortesía. Revista Signo y Seña, 26, pp. 7-22.

18. Lavandera, B. (1988). The social pragmatics of politeness forms. En Ammon, U., Dittmar, N. y Mattheier, K. (Eds.), Sociolinguistics: An international handbook of science of language and society (pp. 1196-1204). Berlín/Nueva York: Walter de Gruyter.

19. Lonkila, M., y Harmo, T. (1999). Toward Computer-Assisted Qualitative Network Analysis. Connections, 22(1), pp. 52-61.

20. Miceli, J. (2008). Los problemas de la validez en el análisis de redes sociales: algunas reflexiones integradoras. Revista Redes, 14(1). DOI: https://doi.org/10.5565/rev/redes.117

21. Ramírez Gelbes, S., y Estrada, A. (2003). Vocativos 'insultivos' vs. vocativos 'insultativos': Acerca del caso de 'boludo'. Anuario de Estudios Filológicos, 26, pp. 335-353.

22. Rendle-Short, J. (2010). 'Mate' as a term of address in ordinary interaction. Journal of Pragmatics, 42, pp. 1201-1218. DOI: https://doi.org/10.1016/j.pragma.2009.09.013

23. Requena Santos, F., y Ávila Muñoz, A. (2002). Redes sociales y sociolingüística. Estudios de sociolingüística, 3(1), pp. 71-90. DOI: https://doi.org/10.1558/sols.v3i1.71

24. Rigatuso, E. (1994). Fórmulas de tratamiento y familia en el español bonaerense actual. Bahía Blanca: Departamento de Humanidades, Universidad Nacional del Sur.

25. Rigatuso, E. (2000). 'Señora (...) ¿no tenés más chico?' Un aspecto de la pragmática de las fórmulas de tratamiento en español bonaerense. Revista Argentina de Lingüística, 16, pp. 293-344.

26. Rigatuso, E. (2011). La constitución del corpus de análisis en estudios de sociolingüística y Pragmática históricas: pasado y presente. En IV Jornadas de Investigación en Humanidades. Homenaje a Laura Laiseca. Bahía Blanca: Departamento de Humanidades, Universidad Nacional del Sur. Recuperado de: http://www.jornadasinvhum.uns.edu.ar/pdf/ACTAS\%20IV\%20JORN ADAS\%20-\%20Completas.pdf.

27. Searle, J. (1977). Actos de habla indirectos. Teorema Revista Internacional de Filosofía, 7, pp. 23-53.

28. Tusón Valls, A. (1995). Análisis de la conversación. Barcelona: Ariel.

29. Verd Pericás, J. M. (s. f.). El uso de la teoría de redes sociales en la representación y análisis de textos. De las redes semánticas al análisis de redes textuales. Empíria. Revista de metodología de ciencias sociales, 10, pp. 129-150. DOI: 


\section{https://doi.org/10.5944/empiria.10.2005.1046}

30. Zimmerman, K. (2005). Construcción de la identidad y anticortesía verbal. Estudio de conversaciones entre jóvenes masculinos. En Bravo, D. (Ed.), Estudios de la (des)cortesía en español: categorías conceptuales y aplicaciones a corpus orales y escritos (pp. 245-271). Buenos Aires: Programa EDICE/DUNKEN.

\section{Anexo. Pautas de transcripción de interacciones en conversaciones coloquiales, basado en Tusón (1995).}

Tabla 1. Símbolos relativos a la prosodia

\begin{tabular}{|l|l|}
\hline$¿ ?$ & Entonación interrogativa \\
\hline$i !$ & Entonación exclamativa \\
\hline$\ldots-$ & Corte abrupto en medio de una palabra \\
\hline $\mid$ & Pausa breve \\
\hline$\|$ & Pausa mediana \\
\hline$<$ pausa $>$ & Pausa larga \\
\hline subr. & Énfasis \\
\hline$::$ & Alargamiento de un sonido \\
\hline
\end{tabular}

Tabla 2. Símbolos relativos a los turnos de palabra

\begin{tabular}{|l|l|}
\hline$:$ & Cambio de voz \\
\hline$==$ & $\begin{array}{l}\text { Al principio de un turno para indicar que no ha habido pausa después } \\
\text { del turno anterior }\end{array}$ \\
\hline $\begin{array}{l}=\ldots= \\
=\ldots=\end{array}$ & Solapamiento en dos turnos \\
\hline
\end{tabular}

Tabla 3. Otros símbolos

\begin{tabular}{|l|l|}
\hline [ ] & $\begin{array}{l}\text { Fenómenos no léxicos, tanto vocales como no vocales. Por ejemplo } \\
\text { [risas] [mirando a B] }\end{array}$ \\
\hline$(())$ & Palabra o frase ininteligible \\
\hline
\end{tabular}

